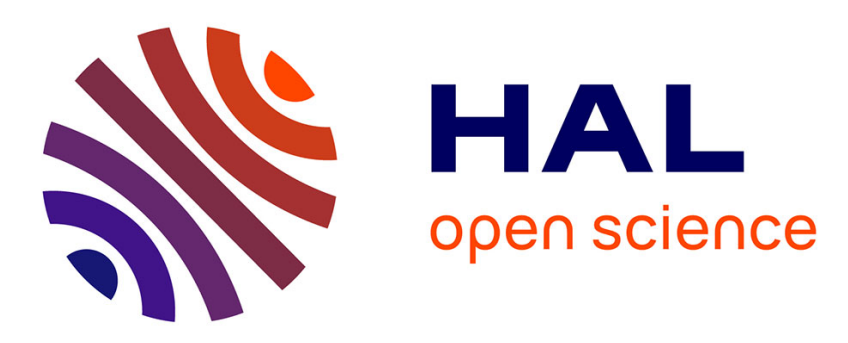

\title{
Mechanical signature and full-field measurement of flow-induced large in-plane deformation of fibrous reinforcements in composite processing
}

\author{
A. Hautefeuille, S. Comas-Cardona, C. Binetruy
}

\section{- To cite this version:}

A. Hautefeuille, S. Comas-Cardona, C. Binetruy. Mechanical signature and full-field measurement of flow-induced large in-plane deformation of fibrous reinforcements in composite processing. Composites Part A: Applied Science and Manufacturing, 2019, 118, pp.213 - 222. 10.1016/j.compositesa.2018.12.030 . hal-03486447

\section{HAL Id: hal-03486447 \\ https://hal.science/hal-03486447}

Submitted on 20 Dec 2021

HAL is a multi-disciplinary open access archive for the deposit and dissemination of scientific research documents, whether they are published or not. The documents may come from teaching and research institutions in France or abroad, or from public or private research centers.
L'archive ouverte pluridisciplinaire HAL, est destinée au dépôt et à la diffusion de documents scientifiques de niveau recherche, publiés ou non, émanant des établissements d'enseignement et de recherche français ou étrangers, des laboratoires publics ou privés.

\section{(ㅇ)(1) $\$$}

Distributed under a Creative Commons Attribution - NonCommerciall 4.0 International 


\title{
Mechanical signature and full-field measurement of flow-induced large in-plane deformation of fibrous reinforcements in composite processing
}

\author{
A. Hautefeuille ${ }^{\mathrm{a}, *}$, S. Comas-Cardona ${ }^{\mathrm{a}}$, C. Binetruy ${ }^{\mathrm{a}}$ \\ ${ }^{a}$ GeM - Research Institute of Civil Engineering and Mechanics, UMR 6183, CNRS - École Centrale de Nantes, 1 rue de la Noé, 44321 Nantes
}

\begin{abstract}
During compression of saturated fibrous reinforcement, the flow of the liquid can, under certain conditions, generate fiber-tows washout (in-plane movement of fiber-tows) due to the strong hydromechanically induced force on the fibrous reinforcement. The objective of the study is first to detect experimentally the onset and measure the full-field magnitude of the flow-induced in-plane deformation occurring during the compression. Secondly, a methodology is presented, aiming at defining the mechanical signature of fiber-tow washout on transverse compression tests. For this purpose, a large-scale semi-transparent test bench has been developed in order to dynamically track the in-plane motion of the fiber-tows occurring in saturated compression. Then, a nomogram is given to identify a process window of a saturated fibrous reinforcement processed by consolidation.
\end{abstract}

Keywords: , B. Optical techniques, C. Transport Phenomena analysis, D. Process monitoring, D. Rheology

\section{Introduction}

A structural composite material arises from the combination of a fibrous reinforcement and an organic liquid matrix. Composite processes must ensure the impregnation of the liquid organic matrix within the fibrous reinforcement. Compression molding belongs to the liquid composite molding (LCM) processes, ensuring the impregnation by consolidation. A fibrous reinforcement (fabric) consists of a collection of tows which themselves contain thousands of fibres. This multi-scale fibrous structure exhibits a high deformability in both out-of-plane and in-plane directions. The cohesion of the fibrous reinforcement is ensured by the friction within the tows and between the tows. The dry fibrous reinforcement also consists of a connected porous network that will be progressively impregnated by the liquid. At the beginning of the impregnation process, the contacts are lubricated by the liquid, reducing the friction [1]. From this lubricated state, the reinforcement will be further saturated during the compression. A wide range of matrices exists, such as molten thermoplastic polymers or thermosetting resins. As a consequence of the developement of such materials, processes involving a resin transfer have to be reliable for a wide range of fluid viscosities from $10^{-2}$ Pa.s for reactive thermosets to more than $25 \mathrm{~Pa}$.s for high fluidity molten thermoplastics [2]. Additionally, in order to answer the high demand for industrial products, processing times are continuously decreasing, leading to high compression velocities and flow rates and therefore a strong mechanical interaction between the fluid and the fibrous architecture. This fluid-solid coupling can induce different flow regimes. When

\footnotetext{
${ }^{*}$ Corresponding author

Email address: alexandre hautef euille@ec-nantes.fr (A. Hautefeuille)
}

the viscosity of the resin and the mold closing velocity are low enough, viscous-drag forces induced by the flow are too low to convect the fiber-tows. A filtration flow occurs (Fig. 1a). Another regime is observable when the viscosity of the resin or the compaction velocity are high enough. The viscous-drag forces become higher than the friction forces and therefore the fiber-tows are convected. In this case, a squeeze flow takes place inducing fiber-tow in-plane washout (tow motion) (Fig. 1b). This kind of flow leads to modifications and inhomogenity in the mechanical properties of the composite part. Thus, the flow regime occurring in the compression process has to be precisely identified and controlled in order to produce flawless high performance parts.

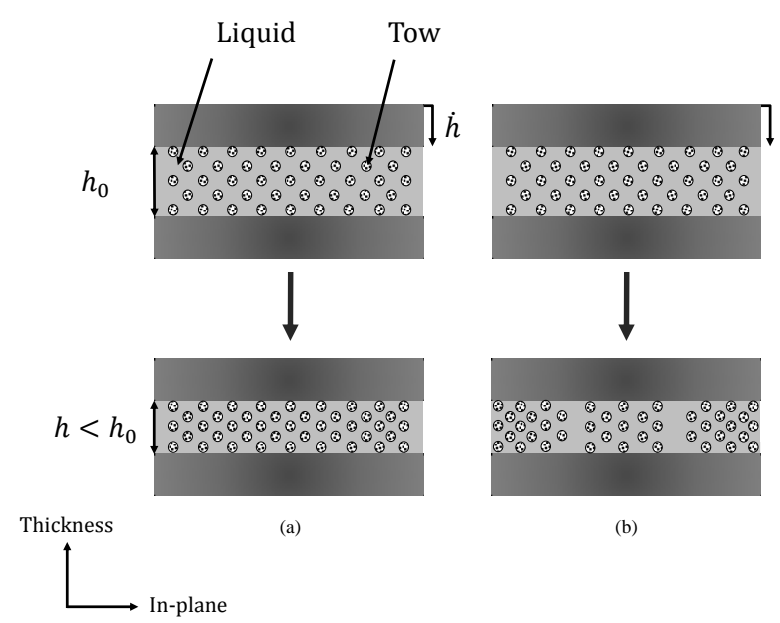

Figure 1: (a) Filtration flow without in-plane fiber-tow motion - (b) Flow with in-plane fiber-tow motion 


\section{Previous work and objectives}

So far the fibre washout phenomenon has mostly been studied during injections in constant cavity thickness processes. The fibrous reinforcement in-plane motion has been visualized by Richardson and Zhang [3] in resin transfer molding (RTM) process, proving that the fibrous reinforcement can move even for reduced injection pressure $\left(P_{i n j} \leqslant 2.5\right.$ bar $)$ for non-woven hemp fibrous reinforcements impregnated with a phenolic resin. Andruweit et al. also vizualized the induced in-plane deformation of bi-axial glass fiber reinforcements during the injection of a low viscosity model fluid, and quantified the maximal injection pressure as a function of the fibre volume fraction [4]. Those studies also demonstrated that the fiber-tow displacements mainly occur close to the injection gate. The phenomenon has also been detected in High Pressure-RTM, where the liquid is injected into the mold cavity with a high pressure $\left(P_{i n j} \geqslant 10\right.$ bar) $[5,6,7]$. Khoun et al. proposed to reduce the fiber-tow displacement with the help of a binder [8]. However, a final misalignment of the tows was still observed for high flow rate injections. In order to prevent or control fiber-tows motion, Restrepo et al. proposed a flow rate and linearly-corrected pressure combined algorithm for fast injection [9]. In a more recent study, Bodaghi et al. proposed a model for fiber-tow washout anticipation during HP-RTM, comparing the fluid and the friction forces [10]. Deformations occurring through thickness have also been studied for RTM process [11]. The authors highlighted the capability of the flow to compress the fibrous reinforcement as soon as the impregnation begins. This phenomenon induces a segregation between the liquid and the fiber-tows. In compression or consolidation processes, the litterature is recent and experimental findings have been proposed by Lawrence et al. [12], observing with a lab-scale compression molding apparatus both lateral and through thickness flow progression, and also the fibrous reinforcement compaction driven by the descent of the top mold. Also, post-process observations of compressed unidirectionnal prepregs reveal the existence of a flow transition mechanism between squeezing and bleeding flows [13]. Moreover, Sorba et al. studied the kinematics of copper threads inserted between plies in unidirectional discontinuous viscous carbon prepreg laminates subjected to through-thickness compression [14]. They highlighted a fiber-tow convecting flow perpendicularly to the tows direction, and a bleeding flow of the resin-rich layers between plies. Those experimental evidences are consistent with the filtration and fiber-tow convecting flow coexistence suggested by Hubert and Poursartip [15] in a comprehensive review of flow and compaction modelling relevant to saturated fibrous reinforcement processing.

Those studies reveal the existence of competing flow mechanisms for various boundary conditions and material behaviors. However, they are either flow visualizations in constant cavity processes or post-consolidation observations. The transient full-field measure of the fibrous reinforcement in-plane motion is not investigated. Moreover, the effect of the washout phenomenon on the compression behavior of the saturated fibrous reinforcement (mechanical signature) has to be characterized in order to detect the phenomenon with blind compression. Blind compression referring to compressions taking place between non-transparent (metallic) platens, as usually performed.

Within this context of visualization and quantification of the in-plane flow induced deformations occurring during unidirectional compression of saturated fibrous reinforcements (isotropic or anisotropic), the main objectives are to:

- Monitor the fibrous reinforcement in-plane motion (washout);

- Detect the fibre motion mechanical signature;

- Determine a process window for any fibrous reinforcement.

\section{Experimental visualizations of flow-induced fiber-tow motion}

\subsection{Raw materials}

A woven fabric (twill-weave, glass fibers, $600 \mathrm{~g} / \mathrm{m}^{2}$ from CHOMARAT) is used. Fibrous reinforcement samples are made with $635 \mathrm{~cm}$-squared fabric plies, leading to a natural thickness around $4.5 \mathrm{~mm}$. The method used to characterize the in-plane hydraulic permeability of such sample was presented by [16], which gives the in-plane equivalent permeability for both isotropic and anisotropic fibrous reinforcements. For any fibrous reinforcement, the in-plane equivalent isotropic permeability $K_{e q}$ is defined by:

$$
K_{e q}=\sqrt{K_{1} K_{2}}
$$

Where $K_{1}$ and $K_{2}$ are the in-plane principal permeabilities, the principal direction 1 and 2 being orthogonal. The transformation from the orthotropic domain $K_{1} \perp K_{2}$ to $K_{e q}$ is detailed in the appendix A. After measurements, the in-plane equivalent isotropic permeability can be expressed as:

$$
K_{e q}\left(V_{f}\right)=4.9 \times 10^{-13} V_{f}^{-6.8}+8.9 \times 10^{-12} 0.30 \leqslant V_{f} \leqslant 0.65
$$

where $V_{f}$ is the fibre volume fraction and $K_{e q}$ in $m^{2}$. The overall volume fractions of the material are shared by the solid phase $\left(V_{f}\right)$ and porosity phase $(\phi)$. At every moment, $V_{f}+\phi=1$. The porosity volume fractions distribution is defined by Eq. (3) for unsaturated fibrous reinforcements (Fig. 10,left), where liquid $\left(\phi_{l}\right)$ and entrapped air $\left(\phi_{\text {air }}\right)$ coexist between and within the fiber-tows.

$$
V_{f}+\phi_{l}+\phi_{\text {air }}=1 \quad \phi=\phi_{l}+\phi_{\text {air }}
$$

For saturated fibrous reinforcements (Fig. 10,right), only liquid fills in the porosity phase $\left(\phi_{\text {air }}=0\right)$. 


$$
V_{f}+\phi_{l}=1 \quad \phi=\phi_{l}
$$

Fibrous reinforcemens samples are saturated ply by ply with a calibrated silicone oil (from Roth company) until a saturation level $V_{l}^{s}$ corresponding to a fibrous reinforcement fibre volume fraction $V_{f}^{s}=35 \%\left(\phi_{l}^{s}=65 \%\right)$. The Fig. 2 illustrates the evolution of the volume fractions of the different phases from the unsaturated to the saturated state of the fibrous reinforcement as the compression takes place. Each oil viscosity has been measured with a Brookfield $D V-1$ viscometer. The Tab. 1 summarizes the viscosity measurements of the calibred fluids used in this study.

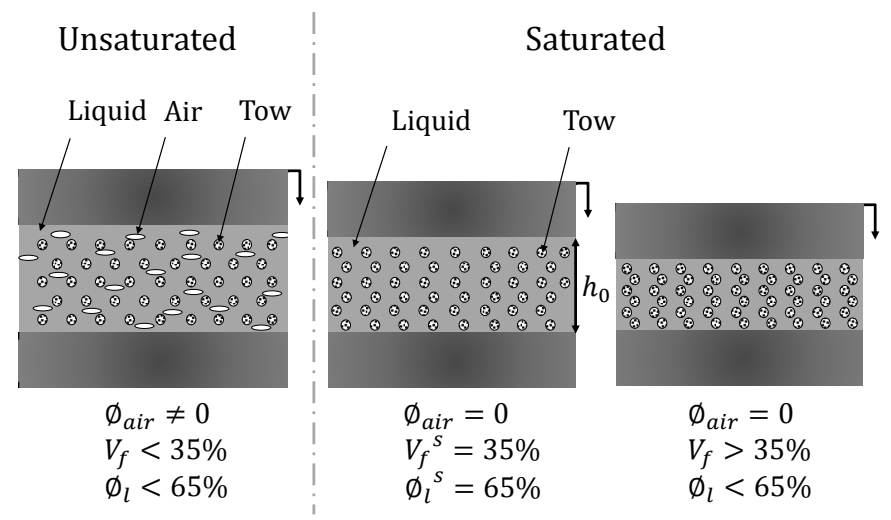

Figure 2: Volume fractions evolution during the fibrous reinforcement compression

Table 1: Silicone oil viscosity measurement in Pa.s at room temperature

\begin{tabular}{lcc}
\hline Fluid ref. & Measured viscosity & Standard deviation \\
\hline M 20 & 0.02 & $1.7 \times 10^{-4}$ \\
M 100 & 0.09 & $7.6 \times 10^{-4}$ \\
M 500 & 0.47 & $2.2 \times 10^{-3}$ \\
M 1000 & 0.93 & $1.6 \times 10^{-3}$ \\
M 5000 & 4.58 & $2.2 \times 10^{-2}$ \\
M 10000 & 9.65 & $1.9 \times 10^{-2}$ \\
\hline
\end{tabular}

\subsection{Experimental setup}

A tempered glass platen has been employed as bottom mold in this study. This $600 \mathrm{~mm}$ diameter glass platen allows the compression of samples up to $400 \mathrm{~mm}$ side length under $200 \mathrm{kN}$ maximal compressive force. The upper platen is a flat disc (150, 300, or $600 \mathrm{~mm}$ diameter mounted) on a ball-joint. The experimental setup is presented in Fig. 3.

The compression tests are operated on an INSTRON 8805 universal testing machine equipped with a $1200 \mathrm{kN}$

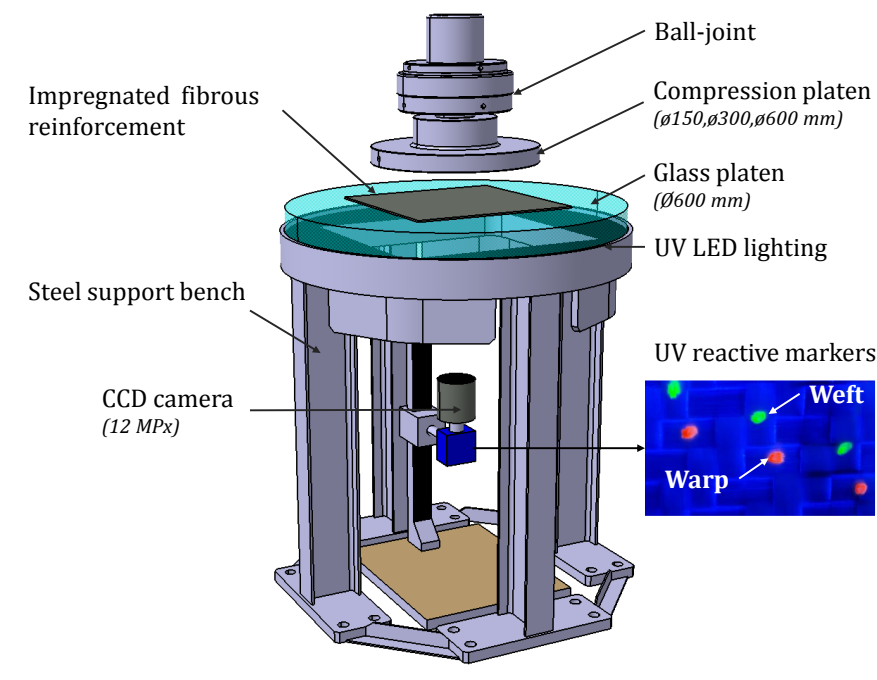

Figure 3: In-plane flow visualization setup

compression load cell, providing precise force-thickness data. As an accurate measure of the sample thickness is required in order to perform precise interpretations, the compliance of the bench is measured and a correction curve is applied over the force range of interest. Below the glass support frame, a 12 MPx CCD color camera records the fibre architecture of the ply in contact with the glass during the compression. This ply is marked with UV-reactive acrylic markers, painted directly one both warp and weft tows with two different colors in order to track the motion of the fiber-tows in each direction. Barrel distortion has been quantified with a chess-grid and the distortion has been evaluated to less than $4 \%$. With the resolution of the camera, the calibration is 1 pixel $=0.1 \mathrm{~mm}$. The saturated fibrous reinforcement samples are placed on the glass platen. Then, the compression with a constant mold closing speed $|\dot{h}|=3 \mathrm{~mm} / \mathrm{min}$ is initiated until a maximal compressive force of $80 \mathrm{kN}$.

\subsection{Fibrous reinforcement tracking algorithm}

In order to quantify the fiber-tows in-plane motion, a tow-tracking algorithm has been developed using Matlab. The flow chart of the algorithm is presented in Fig. 4. This algorithm isolates, in the raw image, warp and weft tows marked with two distant colors in HSV (Hue Saturation Value) color model. Each raw image is segmented so as to detect the centroid of each marker.

Then, centroids are indexed and a $K$-nearest - neighbourg method tracks them from one image to another. An Euclidean distance is computed for the centroid-cloud at each time-step. A final step interpolates the displacement of the fiber-tows between the tracked centroids. Thus, the fiber-tow displacements can be evaluated in both warp and weft directions with a precision of $0.1 \mathrm{~mm}$. 


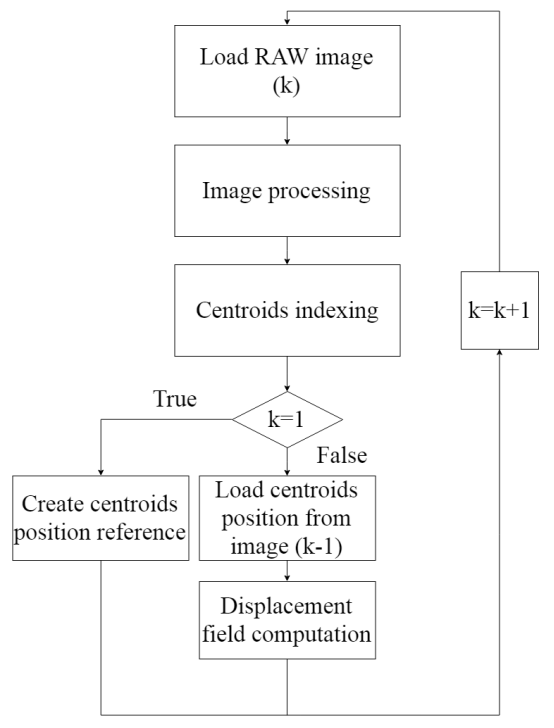

Figure 4: In-plane fibrous reinforcement tracking algorithm flow chart

\subsection{Saturated compression}

During the compression, the generated fluid pressure depends on both materials and process parameters. Experiments summarized in Tab. 2 have been carried out in order to observe first an in-plane stability of the fibrous reinforcement during the consolidation, and secondly an in-plane motion.

Table 2: Experimental parameters

\begin{tabular}{lcc}
\hline Tests & \#A1 & \#A2 \\
\hline Viscosity $(\mu)$ & 0.09 Pa.s & 4.58 Pa.s \\
Saturation level $\left(\phi_{l}^{s}\right)$ & $65 \%$ & $65 \%$ \\
Natural thickness $\left(h_{0}\right)$ & $4.42 \times 10^{-3} \mathrm{~m}$ & $4.0 \times 10^{-3} \mathrm{~m}$ \\
Top platen radius $(R)$ & $15 \times 10^{-2} \mathrm{~m}$ & $15 \times 10^{-2} \mathrm{~m}$ \\
Compression speed $(|\dot{h}|)$ & $3 \mathrm{~mm} / \mathrm{min}$ & $3 \mathrm{~mm} / \mathrm{min}$ \\
Max. compression force $\left(F_{\max }\right)$ & $80 \mathrm{kN}$ & $80 \mathrm{kN}$ \\
\hline
\end{tabular}

A first compression test is realized on the fibrous reinforcement impregnated with a low viscosity fluid $(\mu=$ 0.09 Pa.s). The experimental compressive force and the maximal in-plane displacement magnitude are presented as a function of fibre volume fraction in Fig. 5. The fibrous reinforcement has been compressed around $V_{f}=35 \%$ up to $67 \%$. The compression force versus fibre content $V_{f}$ curve exhibits a power-law dependence.

The fibrous reinforcement displacement magnitude is at maximum $0.9 \mathrm{~mm}$ and remains quite low all along the experiment. This displacement is due to a flattening of tows which induces a little translation of each marker centroid. Moreover, Fig. 6 shows that the field distribution of the in-plane tow motion is quite uniform. The width of the tows being around $3.8 \mathrm{~mm}$, the fibrous reinforcement does not exhibit

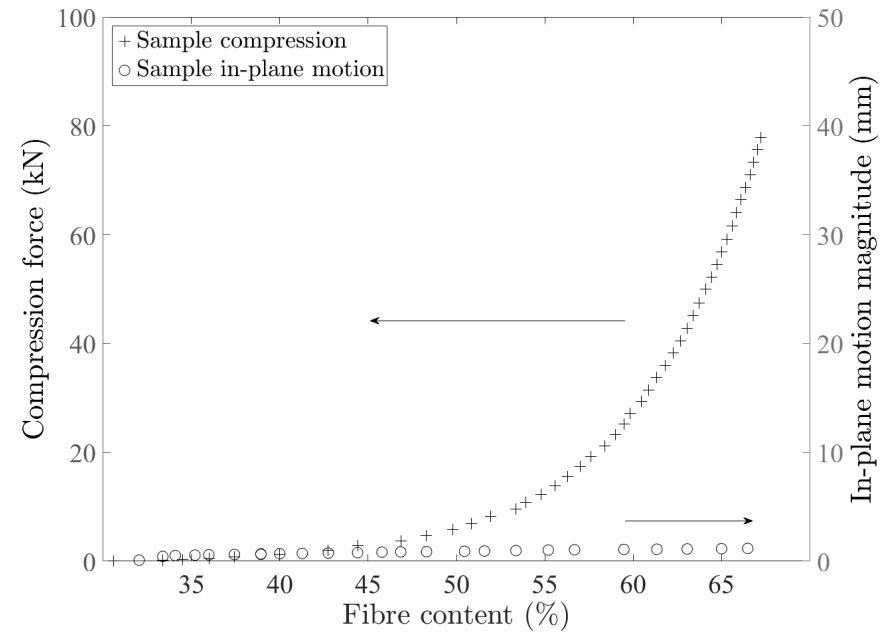

Figure 5: Measured compaction response and in-plane motion of the fiber-tows $(|\dot{h}|=3 \mathrm{~mm} / \mathrm{min}, \mu=0.09$ Pa.s) for Exp.A1

motion during this consolidation experiment. A Darcy's filtration flow in a static fibrous reinforcement occurs.

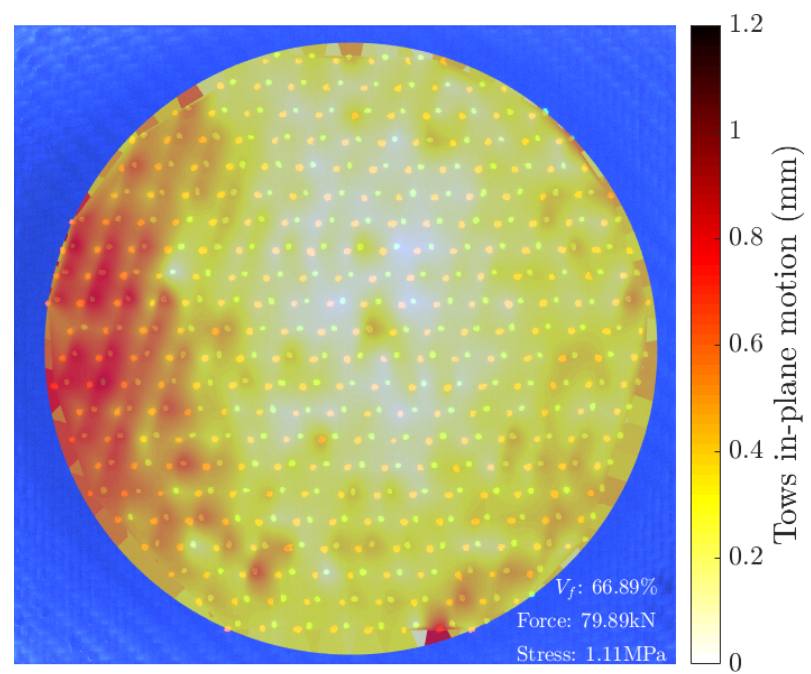

Figure 6: In-plane fiber-tow displacement field at the end of the consolidation $(|\dot{h}|=3 \mathrm{~mm} / \mathrm{min}, \mu=0.09$ Pa.s $)$ for Exp.A1

\subsection{Flow-induced fiber-tow displacement}

As depicted in subsection 3.4, the filtration flow is referred as the first scenario of the study, where the fiber-tows remain static from an in-plane point of view. In order to visualize a fiber-tow convecting flow, one has to generate flow inducing a greater in-plane drag force to fiber-tows. A second test is performed (Exp.A2) with fibrous reinforcement impregnated with a $\mu=4.58$ Pa.s viscosity fluid. The experimental compressive force and the maximal in-plane displacement magnitude are presented in Fig. 7. The fibrous reinforcement has been compressed from $V_{f}=35 \%$ up to $V_{f}=54 \%$.

During this experiment, a fibrous reinforcement in-plane motion is generated as soon as the compression begins. At 


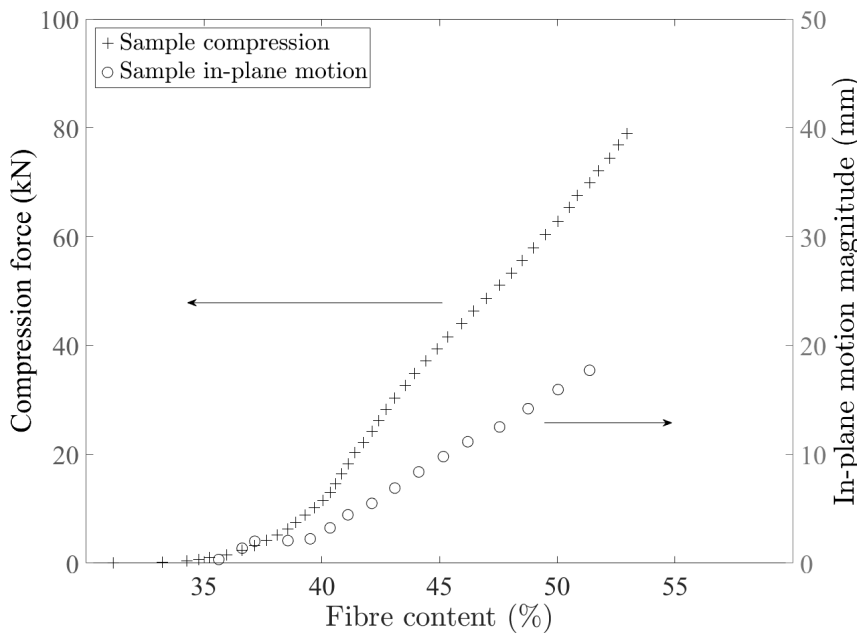

Figure 7: Measured compaction response and in-plane motion of the fiber-tows $(|\dot{h}|=3 \mathrm{~mm} / \mathrm{min}, \mu=4.58 \mathrm{~Pa} . \mathrm{s})$ for Exp.A2

$V_{f}=37 \%$ the in-plane displacement magnitude is already around $3 \mathrm{~mm}$. This magnitude is monotonously increasing up to $19 \mathrm{~mm}$ at the end of the compaction. This result suggests that once the fluid flow starts to convect fiber-tows, the friction forces, even though increased by the compaction of the fibrous reinforcement, are no more sufficient to prevent the fibres washout. In the same time as the fibres motion arises, results plotted in Fig. 7 highlight an unexpected change of slope, around $V_{f}=40 \%$ in the compressive response of the fibrous media. The compression force versus fibre content plot does not exhibit a power-law dependence anymore. The sample seems to adapt its architecture, inducing tows in-plane motion, to minimize its resistance to the fluid flow.

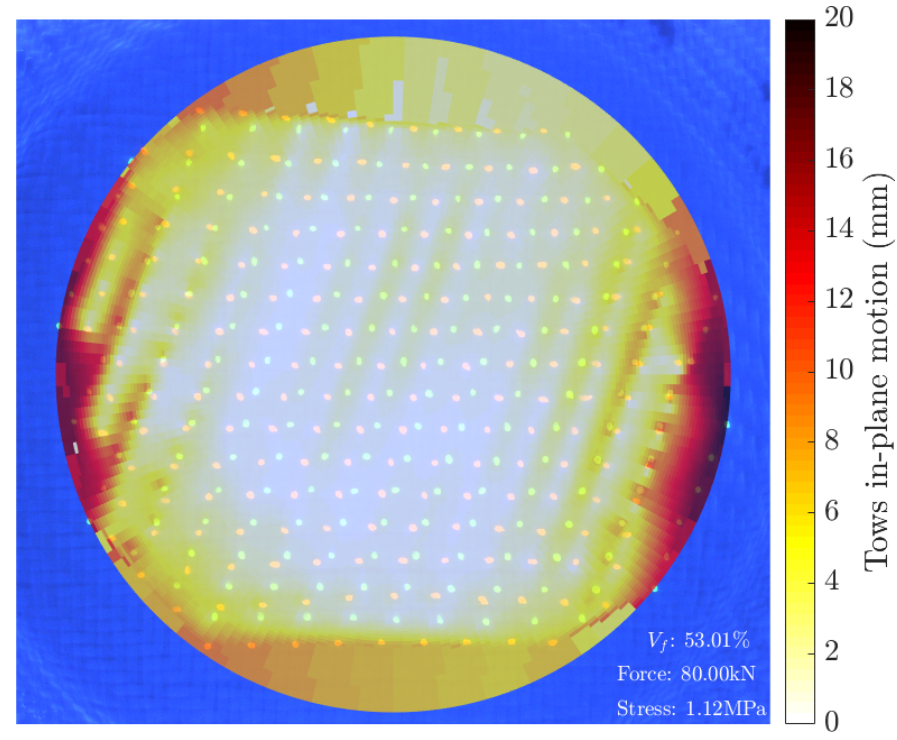

Figure 8: In-plane fiber-tow displacement field at the end of the consolidation $(|\dot{h}|=3 \mathrm{~mm} / \mathrm{min}, \mu=4.58$ Pa.s) for Exp.A2 displacement occurring during the consolidation. First, the in-plane tow motion magnitude increases radially. The viscous flow has convected the fibres along a maximum of $19 \mathrm{~mm}$ in the weft direction and $12 \mathrm{~mm}$ in the warp one at the edges of the compression platen. From those results, one can also see the anisotropy of the material. The fiber-tows in the weft direction strongly limit the fluid flow due to a lower permeability in this direction. Once the drag force becomes stronger than the frictional resistance of the fibrous structure, the latter tends to minimize its resistance to the flow, and to do this, washout begins. Since the permeability is higher in the warp direction, the fluid drag force is lower in this direction and the tows are less convected by the fluid flow.

In this section, the authors aimed to highlight and quantify the washout phenomenon occurring during saturated compression for a given mold closing speed/fluid viscosity. From the compaction curves $\left(F_{z}\right.$ vs $\left.V_{f}\right)$, one can also sense a non-exponentional behavior of the saturated fibrous reinforcement during the consolidation when motion occurs. Thus, a mechanical signature of the in-plane fiber-tows washout seems to be detectable. The following section aims to provide a methodology based on the Darcy's law to detect the in-plane motion of the fibrous reinforcement during compressions with non-transparent platens.

\section{Theory of composite consolidation}

\subsection{Stress distribution}

The stress distribution occurring in a saturated composite consolidation relies on saturated soils mechanics phenomenon described by Biot [17]. All the compression stresses being defined as positive, the overall through-thickness stress acting on a porous medium $\sigma_{z}^{o}$ is found to be equal to the sum of the effective stress $\sigma_{z}^{f}$ due to the springlike reaction of the porous media (fibrous reinforcement) and the hydrostatic pressure $P$ of the liquid contained in the pores:

$$
\sigma_{z}^{o}=\sigma_{z}^{f}+b P
$$

In this equation, the Biot-Willis coefficient $b$ depends on the porous material poroelastic properties [18]:

$$
b=1-\frac{K_{0}}{K_{s}}
$$

where $K_{0}$ and $K_{s}$ represent respectively the bulk modulus of the isotropic porous media as a whole and of the material constituting the porous skeleton (fibres). In the case of a compliant porous media such as a fibrous reinforcement, $K_{s}>>$ $K_{0}$ and Terzaghi effective stress assumption is retrieved $(b=1)$ $[19,20,21]$ :

$$
\sigma_{z}^{o}=\sigma_{z}^{f}+P
$$




\subsection{Fluid flow}

A mathematical model representing the fluid flow in saturated composite consolidation have been developed for high performance structural laminates in autoclave processes [22, 23]. The approach detailled by Gutoswski [24] and by Bickerton [25] has been employed for both Injection/Compression-RTM [26, 27, 28] and preimpregnated fibrous reinforcements consolidation. The three dimensional flow is generated in the porous media by a uni-directional consolidation in the $z$-direction.

The flow of Newtonian fluid through a non-deformable porous material is usually described with Darcy's law [29, 30]:

$$
<v_{l}>-<v_{s}>=-\frac{\underline{\underline{K}}\left(V_{f}\right)}{\mu\left(1-V_{f}\right)} . \nabla P
$$

where $\left\langle v_{l}\right\rangle$ is the interstitial fluid velocity, $\left\langle\boldsymbol{v}_{\boldsymbol{s}}\right\rangle$ is the solid velocity, $\underline{\boldsymbol{K}}$ is the permeability tensor, $\mu$ the viscosity and $V_{f}$ the fibre volume fraction of the fibrous reinforcement. Assuming the fibrous reinforcement only deforms in the thickness direction during the process $\left(<v_{s}>_{x}=<v_{s}>_{y}=0\right)$, Pham [31] derives the expression of the fluid flow from the conservation of both solid and liquid phases:

$$
\nabla \cdot\left[h \frac{K_{e q}\left(V_{f}\right)}{\mu} \nabla P\right]=\dot{h}
$$

The in-plane permeability is defined by $K_{e q}, \dot{h}$ is the tool closing speed (negative because the material is consolidated) and $h$ the thickness of the fibrous reinforcement. Integrating Eq. (9) in cylindrical coordinates with the boudary conditions $P(r)=\left.0\right|_{r=R}$ and $\frac{\partial P}{\partial r}=\left.0\right|_{r=0}$ as shown in Fig. 9 for constant $K_{e q}$ an $\mu$ gives.

$$
P(r)=-\frac{\mu \dot{h}}{4 h K_{e q}\left(V_{f}\right)}\left(R^{2}-r^{2}\right)
$$

In this equation, $r$ defines the radius, varying from $r=0$ at the center and $r=R$ at the extremity of the compression platen. The pressure field solution (Eq. (7)) is presented in Fig. 9.

Hence, the fluid contribution to the effective stress presented in Eq. (7) response can be derived as a fluid force given by:

$$
F_{\text {fluid }}=\int_{0}^{R} 2 \pi r P(r) d r=-\frac{\mu \dot{h} \pi R^{4}}{8 K_{e q}\left(V_{f}\right) h}
$$

For the fibrous reinforcement and unsaturation levels of concern here, the reinforcement is always lubricated (fibres/fibres contacts are lubricated). During compression, the unsaturated reinforcement will become saturated. As shown in (Fig. 10), the compression experimental curves will transition from the lubricated curve to the saturated one depending on the initial saturation level $\phi_{s}^{0}$ defined for compresion tests. The thickness $h_{0}$ corresponds to the saturated volume fraction $V_{f}^{s}$.

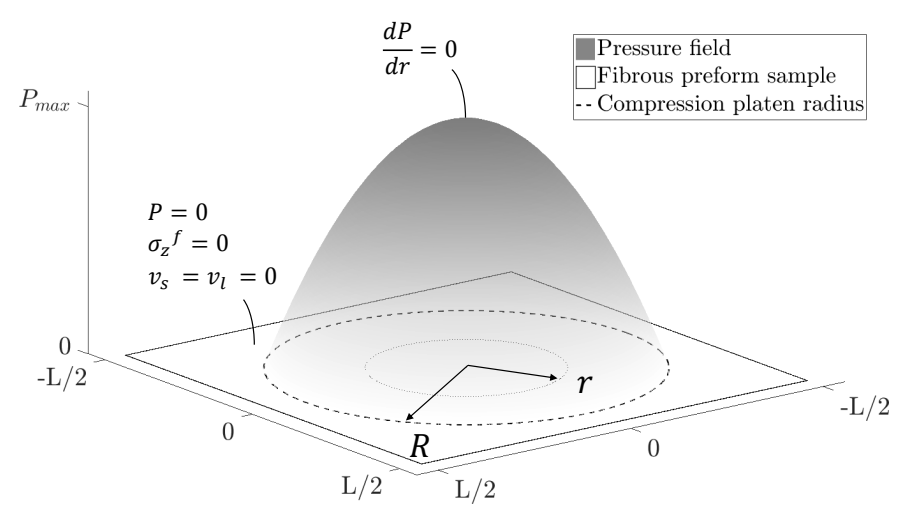

Figure 9: Pressure field obtained by the resolution of Eq. (9) with boundary conditions $P(r=R)=0$ and $\frac{\partial P}{\partial r}=0$ at $r=0$.

The fluid pressure response is calculated by substracting the lubricated fibres response to saturated fibrous reinforcements ones (Fig. 10). Once the fibrous reinforcement is fully saturated, the in-plane permeability can be computed as a function of the porosity, or fibre volume fraction, or thickness from the experimental compression responses:

$$
K_{e q}(h)=-\frac{\mu \dot{h} \pi R^{4}}{8 h\left(F_{z}^{\text {saturated }}-F_{z}^{\text {lubricated }}\right)}
$$

Where $F_{z}^{\text {saturated }}$ and $F_{z}^{\text {lubricated }}$, represent respectively the compression force responses of the saturated fibrous reinforcement and the fibrous reinforcement with lubricated contacts. The choice of using thickness as the variable allows to be independent on the in-plane motion of the fibrous reinforcement since $V_{f}$ varies when fiber-tows washout occurs.

\subsection{Drag force}

In fluid dynamics, the fluid-solid drag force represents the force applied on a solid surface by the surrounding fluid flow. The drag force is proportional to the velocity for a laminar flow. Tucker and Dessenberger defined the volume fluid-solid viscous drag force $f_{\boldsymbol{d}}$ as the difference between the total interaction forces $f_{T}$ and averages of both gravitational $f_{g}$ and averaged pressure $f_{P}$ contributions [30].

$$
f_{d}=f_{T}-f_{g}-f_{P}
$$

Under some simple and realistic assumptions, one can derive the volume in-plane viscous drag force $f_{d}$ as a linear function of the liquid and solid averaged velocity difference [30, 32, 33].

$$
f_{d}=\frac{\mu \phi}{K_{e q}(h)}\left[<v_{l}>-<v_{s}>\right]
$$




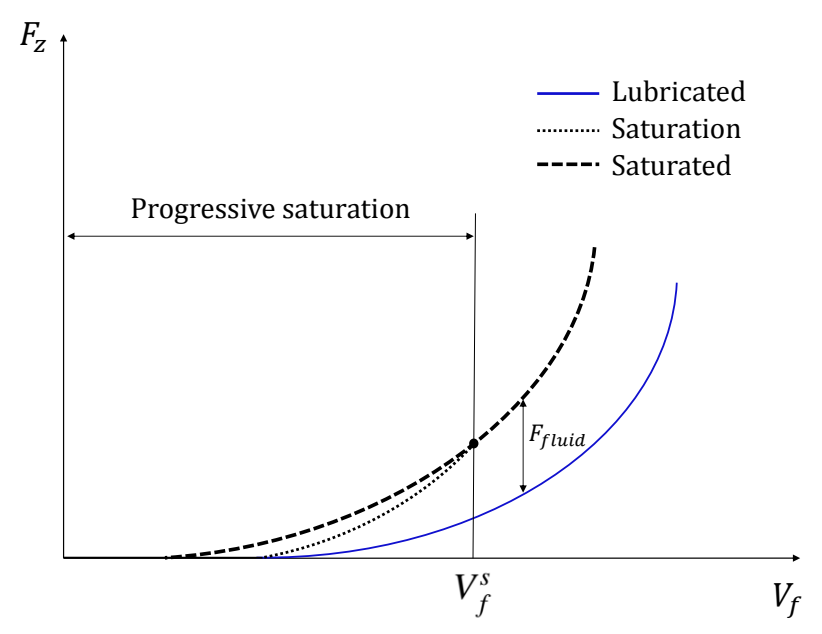

Figure 10: Saturation curves of an impregnated fibrous reinforcement.

When no in-plane motion of the fibrous reinforcement occurs $\left(<v_{s}>=0\right)$, the difference between the two components averaged velocities in Eq. (14) reduces to the fluid interstitial velocity $\left(<v_{l}>\right)$. For a unidirectional compression test, one can equilibrate the volume of fluid expelled $(V)$ from the sample with the reduction of the sample volume:

$$
\frac{d V}{d t}=\frac{d\left(\pi r^{2} h\right)}{d t}=-2 \pi r h \phi<v_{f}>
$$

Paving the way to the estimation of the volume fluid-solid viscous drag force as a function of the flow length, substituting Eq. (15) into Eq. (14) gives:

$$
f_{d}(r)=\frac{\mu|\dot{h}| r}{2 K_{e q}(h) h}
$$

This expression is linear with the fluid interstitial velocity and shows that the fluid-solid drag force increases with the flow length in radial coordinates. This allows to explain the measured field in Fig. 8 which exhibits( higher in-plane motion for large $r$ positions.

\section{Flow-induced deformation mechanical signature}

\subsection{Experimental setup}

In this section, a mechanical signature is sought, based on a precise measure of the fluid response during compression experiments. The flow analysis tests are performed on an INSTRON 5584 universal testing machine equipped with a $100 \mathrm{kN}$ compression load cell. The $15 \mathrm{~cm}$ diameter cylindrical platen compacts the sample until a fibre volume fraction $V_{f}=$ $60 \%$ with a constant compression speed $(3 \mathrm{~mm} / \mathrm{min})$. A receptacle is positioned below the bottom compression platen in order to collect the expelled fluid as the fibrous reinforcement is compressed. The setup is illustrated in Fig. 11. The compression setup deforms during the test. A test without sample is performed to measure the compliance of the setup. The corresponding deformations are substracted to the test measurements over the range of forces applied on the sample.

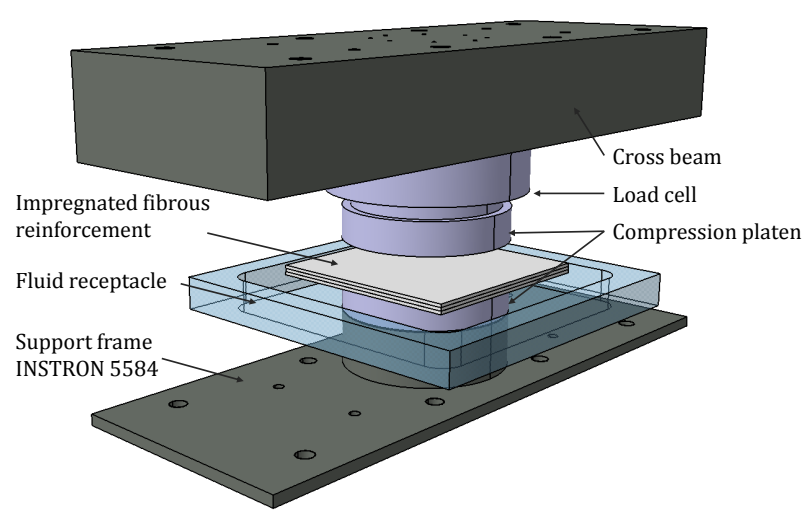

Figure 11: Mechanical signature compression setup

\subsection{Compression tests}

Tab. 3 lists the compression tests parameters. A first compression (Exp.B1) with a very low viscosity fluid is performed first, giving the mechanical response of the lubricated fibrous reinforcement $\left(\sigma_{z}^{f}\right.$ in Eq. (7), or $F_{z}^{\text {lubricated in }}$ Eq. (12)) since the flow-generated pressure of such a fluid is negligible. Further tests are carried out increasing the viscosity and consequently the viscous stress of the fluid (Exp. B2, $\mathrm{B} 3$ and B4). Those tests give the mechanical response $\left(\sigma_{z}^{o}\right.$ in Eq. (7), or $F_{z}^{\text {saturated }}$ in Eq. (12)). Each experiments are repeated three times and the standard deviation is plotted on the compression curves. The results in Fig. 12 show that as expected the total force response is increased as the viscosity increases. Also, the responses show a power-law dependence.

Assuming in a first approach that the material is isotropic, the fibrous media permeability is computed for each test with Eq. (12) and displayed in Fig. 13 along with a baseline curve corresponding to previously measured permeability presented in Eq. (2).

For $V_{f} \leqslant 0.35$ the in-plane permeability is measured for on an unsaturated porous medium. Therefore it diverges from the baseline measured for saturated reinforcement. Once the full saturation level is reached, the calculated hydraulic permeability matches with measured permeability. Under those material/process parameters, the fibrous reinforcement compressions follows the Darcy's law. No in-plane motion of the fibrous reinforcement occurs in those compressive tests as it has been seen in Exp.A1. The compression-induced flow for those fluid viscosity/compression speed couples can be described as filtration flow within a static porous media $\left(v_{s}=0\right)$. 
Table 3: Experimental parameters for fluid viscosities ranging from $\mu=0.02$ to $1 \mathrm{~Pa}$.s

\begin{tabular}{lcccc}
\hline Tests & \#B1(Lub.) & \#B2 & \#B3 & \#B4 \\
\hline Viscosity $(\mu)$ & 0.02 Pa.s & 0.09 Pa.s & $0.47 \mathrm{~Pa} . \mathrm{s}$ & $0.93 \mathrm{~Pa} . \mathrm{s}$ \\
Saturation level $\left(\phi_{s}^{0}\right)$ & $65 \%$ & $65 \%$ & $65 \%$ & $65 \%$ \\
Natural thickness $\left(h_{0}\right)$ & $4.37 \times 10^{-3} \mathrm{~m}$ & $4.42 \times 10^{-3} \mathrm{~m}$ & $4.51 \times 10^{-3} \mathrm{~m}$ & $4.42 \times 10^{-3} \mathrm{~m}$ \\
Compression speed $(|\dot{h}|)$ & $3 \mathrm{~mm} / \mathrm{min}$ & $3 \mathrm{~mm} / \mathrm{min}$ & $3 \mathrm{~mm} / \mathrm{min}$ & $3 \mathrm{~mm} / \mathrm{min}$ \\
Viscous stress $\left(\frac{\mu|\dot{h}|}{h_{0}}\right)$ & $2.3 \times 10^{-4} \mathrm{~Pa}$ & $1.0 \times 10^{-3} \mathrm{~Pa}$ & $5.2 \times 10^{-3} \mathrm{~Pa}$ & $1.1 \times 10^{-2} \mathrm{~Pa}$ \\
\hline
\end{tabular}

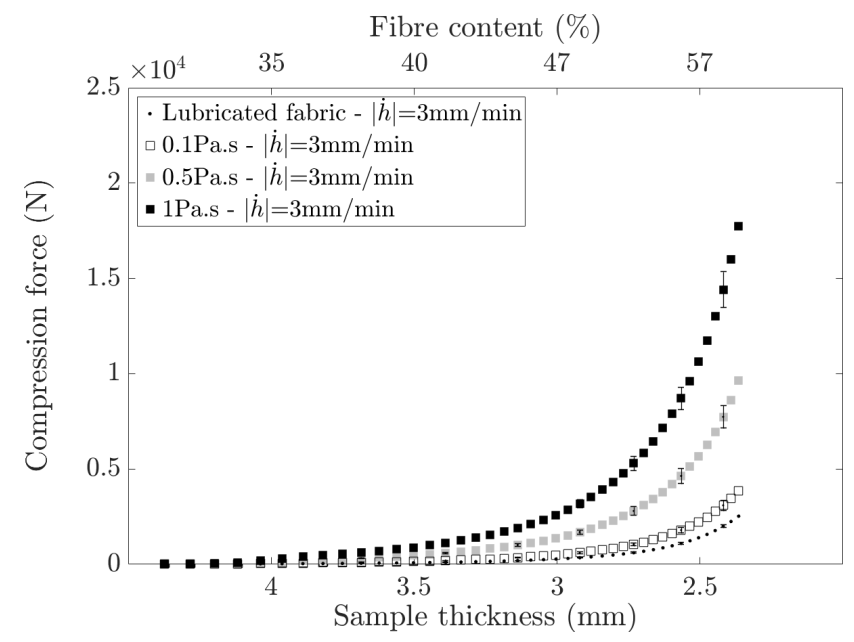

Figure 12: Experimental impregnated fibrous reinforcement total force response for lubricated, $\mu=0.1,0.5$ and $1 \mathrm{~Pa} . \mathrm{s}$ fluid viscosities

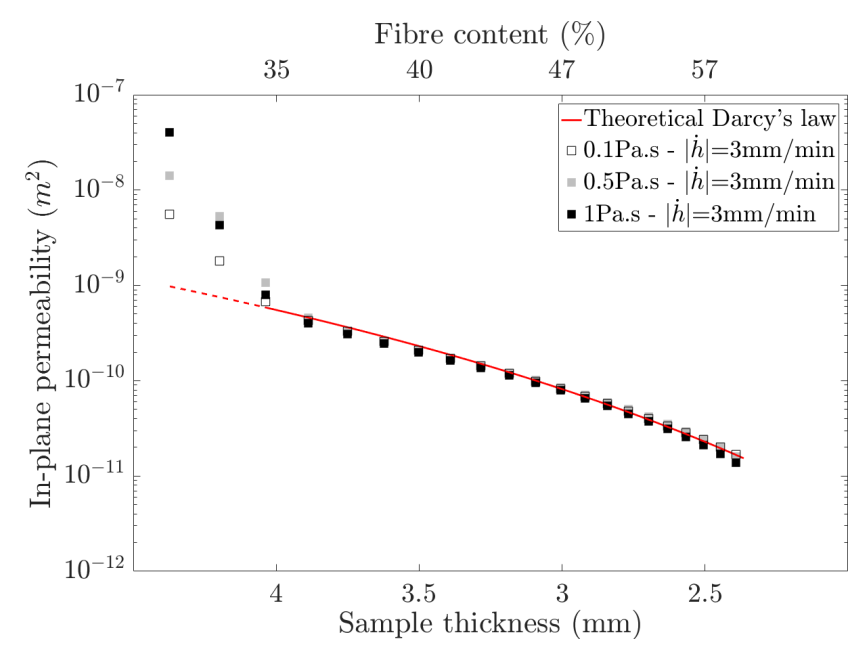

Figure 13: In-plane permeability of the fibrous reinforcement, calculated with Eq. (12) and $\mu=0.1,0.5$ and 1 Pa.s fluid viscosities

\subsection{Increasing the fluid viscosity}

In this section, the viscosity of the saturating fluid is increased to $\mu=5$ and 10 Pa.s, keeping the same initial saturation level $\phi_{s}^{0}=65 \%$ and compression velocity $|\dot{h}|=$ $3 \mathrm{~mm} / \mathrm{min}$ (Tab. 4). The results in Fig. 14 show that the 5 and $10 \mathrm{~Pa} . \mathrm{s}$ saturated fibrous reinforcements do not exhibit a power-law dependence such as low viscosity saturated ones.

Table 4: Experimental parameters for fluid viscosities ranging from $\mu=5$ to 10 Pa.s

\begin{tabular}{lcc}
\hline Tests & \#B5 & \#B6 \\
\hline Viscosity $(\mu)$ & $4.58 \mathrm{~Pa} . \mathrm{s}$ & $9.65 \mathrm{~Pa} . \mathrm{s}$ \\
Saturation level $\left(\phi_{s}^{0}\right)$ & $65 \%$ & $65 \%$ \\
Natural thickness $\left(h_{0}\right)$ & $4.66 \times 10^{-3} \mathrm{~m}$ & $4.71 \times 10^{-3} \mathrm{~m}$ \\
Compression speed $(|\dot{h}|)$ & $3 \mathrm{~mm} / \mathrm{min}$ & $3 \mathrm{~mm} / \mathrm{min}$ \\
Viscous stress $\left(\frac{\mu|\hat{h}|}{h_{0}}\right)$ & $4.9 \times 10^{-2} \mathrm{~Pa}$ & $1.0 \times 10^{-1} \mathrm{~Pa}$ \\
\hline
\end{tabular}

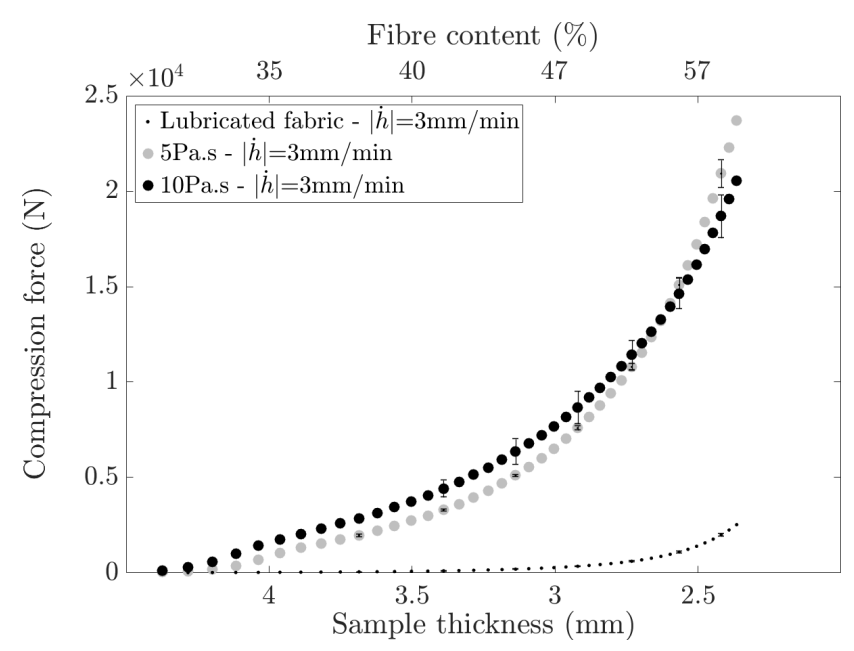

Figure 14: Experimental impregnated fibrous reinforcement total force response for lubricated, $\mu=5$ and $10 \mathrm{~Pa}$.s viscosities

From those compression responses, the computation of the permeability is done following the same methodology as presented above. One can confirm that the permeability results plotted in Fig. 15 do not match anymore with the baseline given 
by the theoretical Darcy's law for static fibrous bed. Comparing with the observations made in Exp.B2 $(\mu=5$ Pa.s, $|\dot{h}|=$ $3 \mathrm{~mm} / \mathrm{min}$ ), the fiber-tows are moving for such parameters. The explanation of such a behavior is that under the unidirectional compressive force, the fibrous reinforcement tends to increase its flow channel size and convects fibres in order to minimise the resistance to the fluid flow. This fibres motion is all the more pronounced as the fluid-solid viscous stress increases.

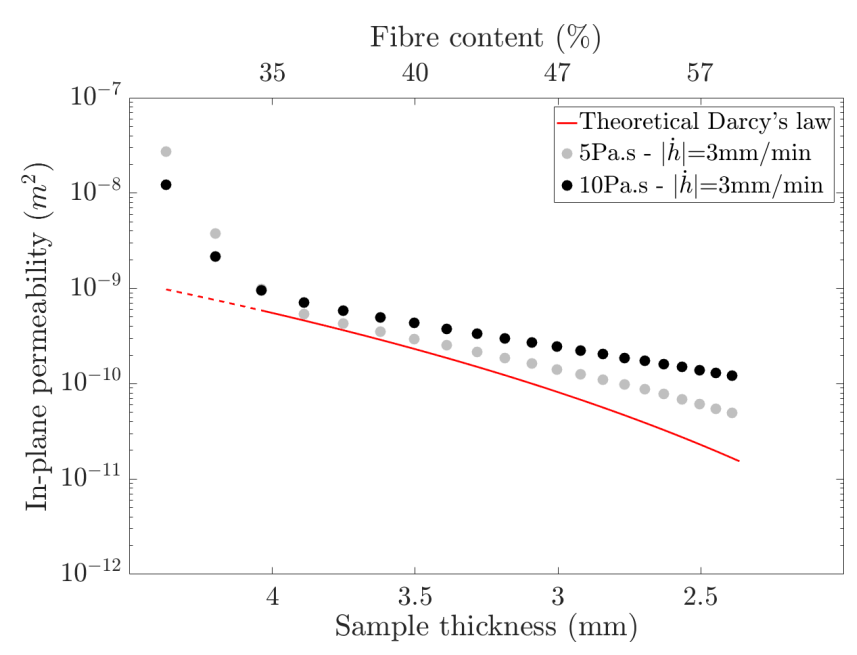

Figure 15: In-plane permeability of the fibrous reinforcement, calculated with Eq. (12) and $\mu=5$ and 10 Pa.s viscosities

In those experiments (Exp.B5, B6), the architecture of the fibrous reinforcement evolves during the compression and the in-plane apparent permeability measurements computed with the compression tests methodology deviates from fundamentals of filtration in a static fibrous material. The fluid force becomes high enougth to convect the fiber-tows and a tow convecting flow occurs, where the velocity of the solid phase is locally no more negligible $\left(v_{s} \neq 0\right)$.

In this section, the mechanical signature of a fiber-tow convecting flow, inducing in-plane washout has been identified. As a consequence of the viscous drag versus friction forces balance, several regimes (filtration or fiber-tows convection) can been distinguished using mechanical compression tests without the use of a transparent mold. Finally one can rank the level of internal cohesion of the saturated fibrous reinforcement when subjected to compression.

\section{Process window determination}

The combination of a fibrous reinforcement, a viscous fluid, and a set of process parameters leads to the determination of a process window for any saturated fibrous reinforcement. A set of experiments has been carried out, varying both the viscosity of the fluid and the compression speed (maintained constant all along each single compression test). The setup presented in section 3 is employed to detect a filtration or a convecting tow flow. The criterion used to distinguish the different regimes is that the motion magnitude has to be lower than a tow width to assume a filtration flow. Then, a processability limit is defined as a function of the compaction speed $|\dot{h}|$, the initial saturated fibrous reinforcement thickness $h_{0}$ (equivalent to the number of plies) and the viscosity of the fluid $\mu$. The results are plotted in Fig. 16. One can sense a transition (dashed line) between the filtration and the convecting tow regimes.

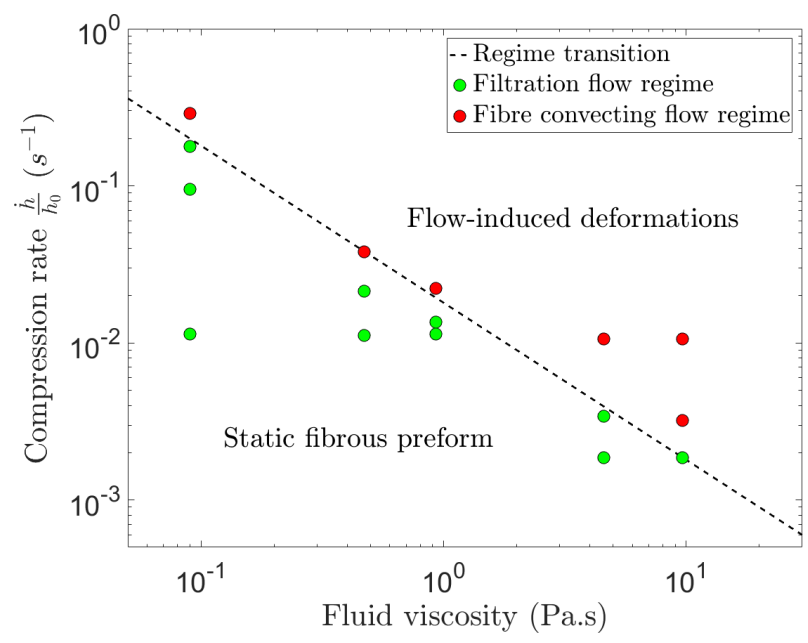

Figure 16: Process window and regimes of the G-WEAVE 600T

For this fibrous material (CHOMARAT G-WEAVE 600T), a safe process window (no in-plane motion) is defined as long as $\frac{|\mu \dot{h}|}{h_{0}} \leq 1.8 \times 10^{-2} \mathrm{~Pa}$. If the viscous stress is higher than the latter value, the fibrous reinforcement will get in motion during the saturated compression.

Within a process optimization context, one would to control the viscous stress generated by the fluid in order to ensure the in-plane motionlessness of the tows during the compression. Also for increased productivity, an accurate move consists in generating a flow within a static fibrous bed with the greatest compaction speed. Fig. 17 illustrates a process window for saturated compressions.

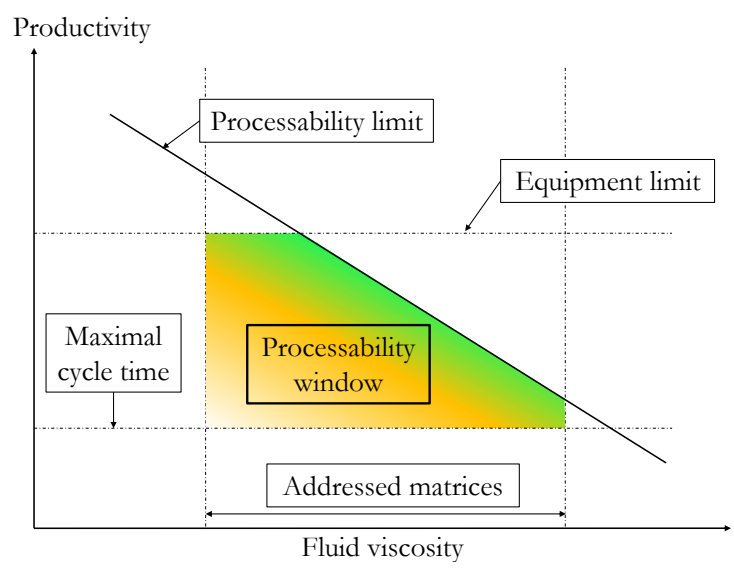

Figure 17: Process window determination 
The regime transition from a flow within a static fibrous bed and a convecting tow one gives the upper boundary of the process window. The bottom one arises from the maximal acceptable time for a compression cycle. Therefore, a process window is established for the studied fibrous material.

\section{Conclusion}

In this paper, a methodology has been presented in order to detect a convecting tow flow regime, inducing washout in a deformable saturated fibrous reinforcement. Those results can explain unexpected compression curves during unidirectional compression of saturated fibrous reinforcements. Experimental results demonstrate that the mechanical signature of the tow motion is detectable with a quick analytical calculation of the fibrous reinforcement in-plane permeability. Thus, several flow regimes can be distinguished depending on the stability or the motion of the fibrous reinforcement. The Fig. 18 illustrates the detection of the washout (motion) phenomenon.

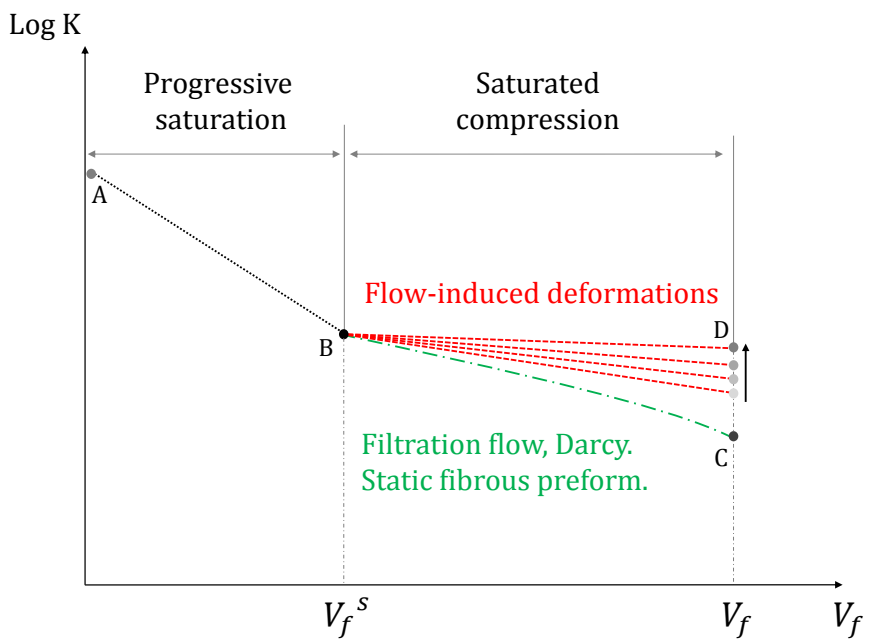

Figure 18: Regime distinction based on the mechanical response of the saturated fibrous reinforcement

As the material is compressed, the saturation of the fibrous reinforcement occurs from the natural fibre volume fraction of the material (A) to the saturated fibre volume fraction $(\mathbf{B})$. Then, a fluid flow occurs in the saturated media. Depending on the fluid-solid viscous stress, a filtration flow in a static bed (B-C) or fiber-tow convecting flow (B-D) occurs. The in-plane washout of the fibrous reinforcement during consolidation opens the flow channels within the fibrous reinforcement, in order to reduce the resistance of the fibrous reinforcement to the flow. Thus, the apparent in-plane permeability is modified and does not follow the Darcy's law in a static fibrous bed anymore. Experiments also show that the onset of fiber-tows washout is to be at the beginning of the compression, while the lubricated friction forces are not high enough to balance the fluid-solid drag force. As a perspective of this experimental study, the friction forces have to be studied during composite consolidation.

\section{Appendix A: Transformation of a orthotropic domain}

For continuous transverse compression of a saturated porous media, the fluid pressure is governed by the continuity equation combined with the Darcy's law and writes:

$$
K_{1} \frac{\partial^{2} P}{\partial x^{2}}+K_{2} \frac{\partial^{2} P}{\partial y^{2}}=\mu \frac{\dot{h}}{h}
$$

where $K_{1}$ and $K_{2}$ are the two principal in-plane permeabilities, $P$ the fluid pressure, $\mu$ the fluid viscosity, $h$ the thickness and $\dot{h}$ the compression speed. Using the change of variable given in Eq. (18) [34] transforms the orthotropic consolidation in an equivalent isotropic one. That change of variable ensures a conservation of the consolidation area.

$$
\begin{array}{ll}
\bar{x}=x\left(\frac{K_{2}}{K_{1}}\right)^{\frac{1}{4}} & \bar{y}=y\left(\frac{K_{1}}{K_{2}}\right)^{\frac{1}{4}} \\
\frac{\partial \bar{x}}{\partial x}=\left(\frac{K_{2}}{K_{1}}\right)^{\frac{1}{4}} & \frac{\partial \bar{y}}{\partial y}=\left(\frac{K_{1}}{K_{2}}\right)^{\frac{1}{4}}
\end{array}
$$

Using the chain rule of derivatives, the symmetry of the second derivatives and Eq. (19), the x-term and the y-term of the left-hand side of Eq. (17) respectively write:

$$
\begin{array}{rlrl}
K_{1} \frac{\partial^{2} P}{\partial x^{2}} & =K_{1} \frac{\partial}{\partial x}\left(\frac{\partial P}{\partial x}\right) & K_{2} \frac{\partial^{2} P}{\partial y^{2}} & =K_{2} \frac{\partial}{\partial y}\left(\frac{\partial P}{\partial y}\right) \\
& =K_{1} \frac{\partial}{\partial x}\left(\frac{\partial P}{\partial \bar{x}} \frac{\partial \bar{x}}{\partial x}\right) & & =K_{2} \frac{\partial}{\partial y}\left(\frac{\partial P}{\partial \bar{y}} \frac{\partial \bar{y}}{\partial y}\right) \\
& =K_{1}\left(\frac{K_{2}}{K_{1}}\right)^{\frac{1}{4}} \frac{\partial}{\partial x}\left(\frac{\partial P}{\partial \bar{x}}\right) & & =K_{2}\left(\frac{K_{1}}{K_{2}}\right)^{\frac{1}{4}} \frac{\partial}{\partial y}\left(\frac{\partial P}{\partial \bar{y}}\right) \\
& =K_{1}\left(\frac{K_{2}}{K_{1}}\right)^{\frac{1}{4}} \frac{\partial}{\partial \bar{x}}\left(\frac{\partial P}{\partial x}\right) & & =K_{2}\left(\frac{K_{1}}{K_{2}}\right)^{\frac{1}{4}} \frac{\partial}{\partial \bar{y}}\left(\frac{\partial P}{\partial y}\right) \\
& =K_{1}\left(\frac{K_{2}}{K_{1}}\right)^{\frac{1}{4}} \frac{\partial}{\partial \bar{y}}\left(\frac{\partial P}{\partial \bar{y}} \frac{\partial \bar{y}}{\partial y}\right) \\
& \left.=K_{1}\left(\frac{K_{2}}{K_{1}}\right)^{\frac{1}{2}} \frac{\partial^{2} P}{\partial \bar{x}^{2}}\right) & & =K_{2}\left(\frac{K_{1}}{K_{2}}\right)^{\frac{1}{2}} \frac{\partial^{2} P}{\partial \bar{y}^{2}} \\
& =\sqrt{K_{1} K_{2}} \frac{\partial^{2} P}{\partial \bar{x}^{2}} & & \sqrt{K_{1} K_{2}} \frac{\partial^{2} P}{\partial \bar{y}^{2}} \\
& =K_{e q} \frac{\partial^{2} P}{\partial \bar{x}^{2}} & =K_{e q} \frac{\partial^{2} P}{\partial \bar{y}^{2}}
\end{array}
$$

Where $K_{e q}$ is the equivalent isotropic in-plane permeability defined as:

$$
K_{e q}=\sqrt{K_{1} K_{2}}
$$


The orthotropic system governing equation reduces to the isotropic one:

$$
K_{e q}\left(\frac{\partial^{2} P}{\partial \bar{x}^{2}}+\frac{\partial^{2} P}{\partial \bar{y}^{2}}\right)=\mu \frac{\dot{h}}{h}
$$

\section{Acknowledgement}

Part of this study is funded by FUI-AAP20 Regions Projects (France) within the INCREASE project (partners: Solvay, IFTH, Billion SAS, Pernoud, Chomarat Textiles Industries, IPC, INSA Lyon and Centrale Nantes)

\section{References}

[1] P. Kelly, R. Umer, and S. Bickerton, "Viscoelastic response of dry and wet fibrous materials during infusion processes," Composites Part A: Applied Science and Manufacturing, vol. 37, no. 6, pp. 868-873, 2006.

[2] K. Van Rijswijk and H. Bersee, "Reactive processing of textile fiber-reinforced thermoplastic composites-an overview," Composites Part A: Applied Science and Manufacturing, vol. 38, no. 3, pp. 666-681, 2007.

[3] M. Richardson and Z. Zhang, "Experimental investigation and flow visualisation of the resin transfer mould filling process for non-woven hemp reinforced phenolic composites," Composites Part A: Applied Science and Manufacturing, vol. 31, no. 12, pp. 1303-1310, 2000.

[4] A. Endruweit, S. Gehrig, and P. Ermanni, "Mechanisms of hydrodynamically induced in-plane deformation of reinforcement textiles in resin injection processes," Journal of composite materials, vol. 37, no. 18, pp. 1675-1692, 2003.

[5] B. Gourichon, C. Binetruy, and P. Krawczak, "Experimental investigation of high fiber tow count fabric unsaturation during rtm," Composites Science and Technology, vol. 66, no. 7-8, pp. 976-982, 2006.

[6] P. Rosenberg, R. Chaudhari, M. Karcher, F. Henning, and P. Elsner, "Investigating cavity pressure behavior in high-pressure $\mathrm{rtm}$ process variants," AIP Conference Proceedings, vol. 1593, no. 1, pp. 463-466, 2014.

[7] H. Aimé, Experimental study and modeling of fibrous preform deformation during high-pressure RTM. Theses, Ecole Centrale de Nantes (ECN), Dec. 2014.

[8] L. Khoun, D. Maillard, and M. N. Bureau, "Effect of process variables on the performance of glass fibre reinforced composites made by high pressure resin transfer moulding," in Proceedings of the 12th Annual Automotive Composites Conference and Exhibition (ACCE 2012), 2012.

[9] O. Restrepo, K.-T. Hsiao, A. Rodriguez, and B. Minaie, "Development of adaptive injection flow rate and pressure control algorithms for resin transfer molding," Composites Part A: Applied Science and Manufacturing, vol. 38, no. 6, pp. 1547-1568, 2007.

[10] M. Bodaghi, P. Simacek, S. G. Advani, and N. C. Correia, "A model for fibre washout during high injection pressure resin transfer moulding," Journal of Reinforced Plastics and Composites, p. 0731684418765968, 2018.

[11] K. Han, L. Trevino, L. J. Lee, and M. Liou, "Fiber mat deformation in liquid composite molding. i: Experimental analysis," Polymer composites, vol. 14, no. 2, pp. 144-150, 1993.

[12] J. Lawrence, P. Simacek, and S. Advani, "The compression resin transfer molding process for automotive composite components," ASC Series on Advances in Composite Materials: Vol. 6, Manufacturing of Composites, vol. 6, p. 143, 2013.

[13] J.-H. Belnoue, O. Nixon-Pearson, D. Ivanov, and S. Hallett, "A novel hyper-viscoelastic model for consolidation of toughened prepregs under processing conditions," Mechanics of Materials, vol. 97, pp. 118-134, 2016.

[14] G. Sorba, C. Binetruy, A. Leygue, and S. Comas-Cardona, "Squeeze flow in heterogeneous unidirectional discontinuous viscous prepreg laminates: Experimental measurement and 3d modeling," Composites Part A: Applied Science and Manufacturing, vol. 103, pp. 196-207, 2017.
[15] P. Hubert and A. Poursartip, "A review of flow and compaction modelling relevant to thermoset matrix laminate processing," Journal of Reinforced Plastics and Composites, vol. 17, no. 4, pp. 286-318, 1998.

[16] S. Comas-Cardona, C. Binetruy, and P. Krawczak, "Unidirectional compression of fibre reinforcements. part 2: A continuous permeability tensor measurement," Composites Science and Technology, vol. 67, no. 3, pp. 638-645, 2007.

[17] M. Biot, "Theory of elasticity and consolidation for a porous anisotropic solid," Journal of applied physics, vol. 26, no. 2, pp. 182-185, 1955.

[18] M. Biot and D. Willis, "The elastic coefficients of the theory of consolidation," J. appl. Mech, vol. 24, pp. 594-601, 1957.

[19] K. Terzaghi, R. B, and Peck, Soil mechanics in engineering practice. John Wiley And Sons, Inc.; New York, 1948.

[20] T. Tran, C. Binetruy, S. Comas-Cardona, and N.-E. Abriak, "Microporomechanical behavior of perfectly straight unidirectional fiber assembly: Theoretical and experimental," Composites Science and Technology, vol. 69, no. 2, pp. 199-206, 2009.

[21] T. Tran, S. Comas-Cardona, N.-E. Abriak, and C. Binetruy, "Unified microporomechanical approach for mechanical behavior and permeability of misaligned unidirectional fiber reinforcement," Composites Science and Technology, vol. 70, no. 9, pp. 1410-1418, 2010.

[22] R. Dave, J. Kardos, and M. Duduković, "A model for resin flow during composite processing: Part 1general mathematical development," Polymer Composites, vol. 8, no. 1, pp. 29-38, 1987.

[23] T. Gutowski, T. Morigaki, and Z. Cai, "The consolidation of laminate composites," Journal of Composite Materials, vol. 21, no. 2, pp. 172-188, 1987.

[24] T. Gutowski, Z. Cai, S. Bauer, D. Boucher, J. Kingery, and S. Wineman, "Consolidation experiments for laminate composites," Journal of Composite Materials, vol. 21, no. 7, pp. 650-669, 1987.

[25] S. Bickerton and P. Kelly, "Compression resin transfer moulding (crtm) in polymer matrix composites," in Manufacturing techniques for polymer matrix composites (PMCs), pp. 348-380, Elsevier, 2012.

[26] S. Bickerton and M. Abdullah, "Modeling and evaluation of the filling stage of injection/compression moulding," Composites Science and technology, vol. 63, no. 10, pp. 1359-1375, 2003.

[27] M. Deleglise, C. Binetruy, and P. Krawczak, "Simulation of lcm processes involving induced or forced deformations," Composites Part A: Applied Science and Manufacturing, vol. 37, no. 6, pp. $874-880$, 2006. Selected Contributions from the 7th International Conference on Flow Processes in Composite Materials held at University of Delaware, USA.

[28] M. Buntain and S. Bickerton, "Modeling forces generated within rigid liquid composite molding tools. part a: Experimental study," Composites Part A: Applied Science and Manufacturing, vol. 38, no. 7, pp. 1729-1741, 2007.

[29] H. Darcy, Les fontaines publiques de la ville de Dijon: exposition et application... Victor Dalmont, 1856.

[30] C. Tucker, R. Dessenberger, et al., "Governing equations for flow and heat transfer in stationary fiber beds," Composite Materials Series, pp. 257-257, 1994.

[31] X.-T. Pham, F. Trochu, and R. Gauvin, "Simulation of compression resin transfer molding with displacement control," Journal of reinforced plastics and composites, vol. 17, no. 17, pp. 1525-1556, 1998.

[32] J. C. Slattery, "Flow of viscoelastic fluids through porous media," AIChE Journal, vol. 13, no. 6, pp. 1066-1071, 1967.

[33] K. M. Pillai, "Governing equations for unsaturated flow through woven fiber mats. part 1. isothermal flows," Composites Part A: Applied Science and Manufacturing, vol. 33, no. 7, pp. 1007-1019, 2002.

[34] J. Weitzenböck, R. Shenoi, and P. Wilson, "Radial flow permeability measurement. part a: Theory," Composites Part A: Applied Science and Manufacturing, vol. 30, no. 6, pp. 781-796, 1999. 